\title{
Elementos da História da Química do Século XVIII*
}

Geralmente, os historiadores consideram que a química só se constituiu como disciplina científica no século XVIII, ligando a este acontecimento o nome de Antoine-Laurent Lavoisier (1743-1794) (fig.1).

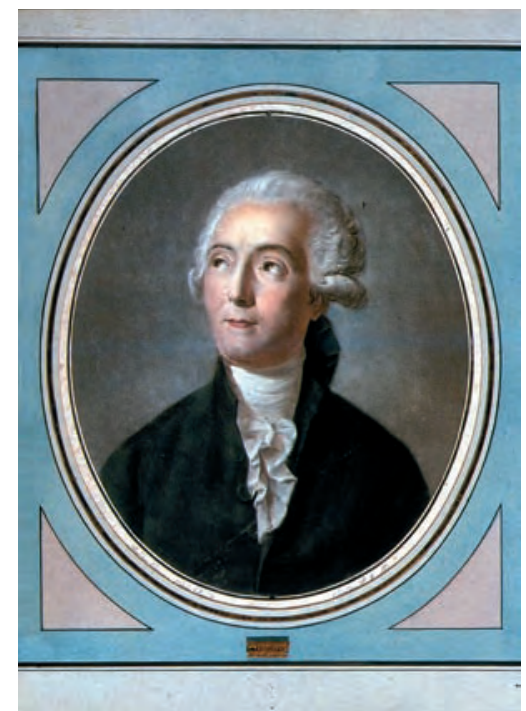

Figura 1 Retrato de Lavoisier (Panopticum Lavoisier, http://moro.imss.fi.it/lavoisier/ entrance/panobox.html)

Concordemos ou não com esta leitura, é consensual que, no âmbito da filosofia natural, a química esteve imersa em problemas de difícil resolução até ao século XVIII: a grande variedade e com-

*Conferência proferida por ocasião da estreia da peça "Oxigénio" de Carl Djerassi e Roald Hoffman, no Teatro do Campo Alegre do Porto a 19-01-2006.

${ }^{1}$ Centro de História e Filosofia da Ciência e da Tecnologia, Faculdade de Ciências e Tecnologia Universidade Nova de Lisboa 2825-114 Monte de Caparica plexidade das substâncias tornavam difíceis quaisquer generalizações; não havia uma distinção entre ácidos, bases e sais; não existia o conceito de gás; o conceito de pureza era inexistente; não havia uma linguagem química universalmente aceite; a insuficiência de técnicas analíticas e de ferramentas conceptuais era de difícil ultrapassagem. No entanto, é no século das Luzes que esta paisagem se irá alterar profundamente. Para uma melhor compreensão da situação da química no século XVIII, começarei por analisar sumariamente 0 artigo "Chymie" ${ }^{1}$ da autoria de Gabriel François Venel (1723-1775), publicado em 1753, na Encyclopédie (fig. 2), editada por Denis Diderot (1713-1784) e Jean Le Rond d'Alembert (1717-1783) para passar, depois, às principais contribuições de Lavoisier no contexto da sua época. ${ }^{2}$

\section{A química na Encyclopédie - uma revolução esperada}

A Encyclopédie (1751-1772) de Diderot e d'Alembert é uma obra emblemática da sua época. Publicada em francês e já não em latim, até ali a língua dos eruditos, pretendia dar a todos aqueles que a pudessem ler os conhecimentos mais recentes nas artes, ciências e ofícios. 0 conhecimento, entendido como condição essencial à felicidade dos homens, foi apresentado nesta obra de forma racional e sistemática, ordenado alfabeticamente para maior comodidade do leitor. Gabriel Venel, médico e professor da Universidade de Montpellier, foi incumbido pelos editores de escrever a entrada "Chymie". Nela, Venel faz um diagnóstico bastante preciso da situação da química em meados do século XVIII e dos dilemas a enfrentar: ${ }^{3}$

Figura 2 Frontispício da Encyclopédie e página do artigo "Chymie"da autoria de Venel
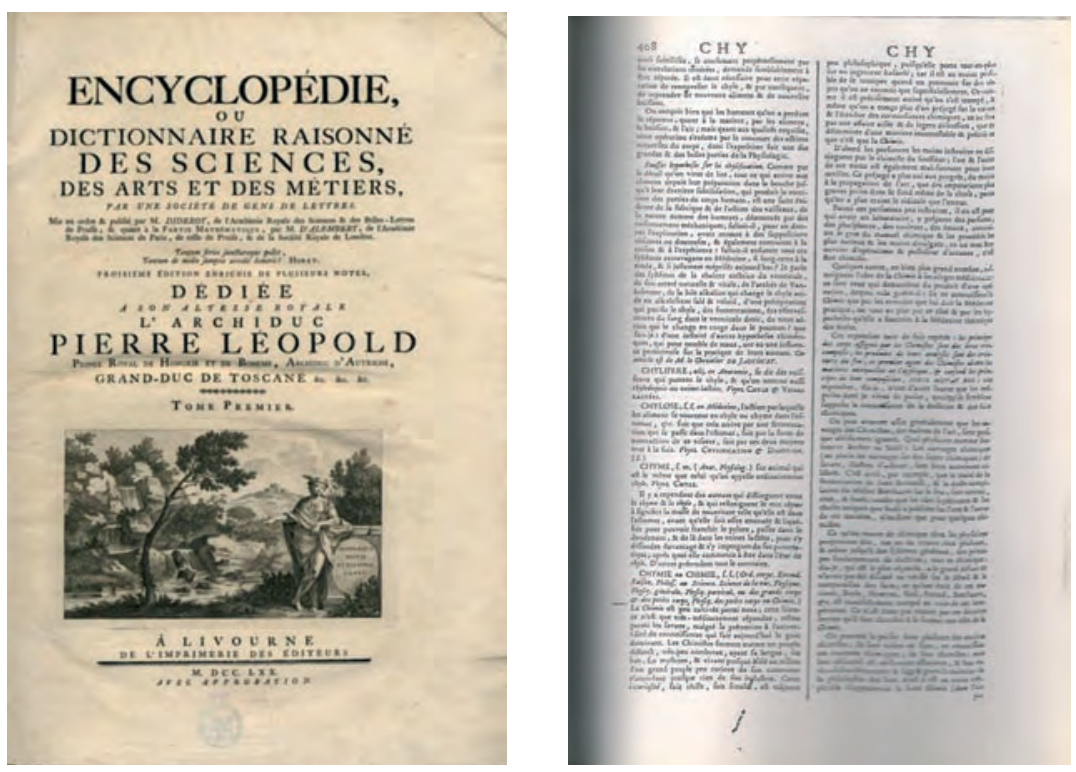
É verdade que a revolução capaz de colocar a química ao nível do que ela merece, pelo menos ao lado da física calculada, só pode ser operada por um químico hábil, entusiasta e audaz que, encontrando-se numa posição favorável e aproveitando algumas circunstâncias felizes, possa despertar a atenção dos filósofos por meio de uma ostentação brilhante, por um tom decidido e afirmativo e, em seguida, por razões válidas se as primeiras tiverem destruído o preconceito.

Vemos assim que, em 1753, se esperava uma revolução na química. A ideia de revolução era comum nesta altura, mas o que é novidade em Venel é que a revolução não é descrita no passado, mas no futuro, e não significava uma alteração total da teoria em vigor. A acção revolucionária consistiria, antes, numa campanha de opinião, uma estratégia de promoção da química para elevá-la à dignidade enciclopédica. ${ }^{4}$ Venel não esperava um herói revolucionário que fundasse uma nova teoria, mas uma elevação do prestígio social da química, até ali envolta em preconceito: entre gente instruída, o químico era confundido com o metalúrgico e o vidreiro; no contexto da filosofia natural, a química era demasiado subserviente da mecânica. Venel prossegue com uma longa comparação entre a química e a física, afirmando que na exposição dos fenómenos o químico e o físico só dizem coisas diferentes, mas não contraditórias. Perante um corpo, os físicos só veriam as qualidades exteriores, acidentais, encará-lo-iam como uma massa obediente às leis da mecânica; ao invés, um químico atenderia às suas qualidades interiores e específicas, estaria preocupado em revelar as suas partes integrantes, governadas por princípios não mecânicos. ${ }^{5}$ Contrastando as duas abordagens, Venel termina, afirmando: ${ }^{6}$

Numa palavra, o génio físico elevado ao mais alto grau que a humanidade pode atingir produzirá os Principia de Newton; o extremo correspondente do génio químico é o specimen becherianum de Stahl.

De facto, até Lavoisier e mesmo depois, a química foi marcada por dois modos de abordagem da matéria e das suas transformações, por vezes coexistindo num mesmo indivíduo: um decorrente da tradição Becher-Stahl; o outro saído das doutrinas corpusculares da matéria e da mecânica newtoniana.

Nos princípios do século XVIII, Georg Ernst Stahl (1660-1734), médico do Rei da Prússia, considerava que a química não poderia ser reduzida aos princípios da mecânica, defendendo uma filosofia da natureza baseada na química. Fez uma distinção que se revelou essencial à definição do objecto da química, a distinção entre agregados e mistos. Os primeiros eram substâncias homogéneas, cuja formação se devia a acções mecânicas; os segundos, substâncias heterogéneas (misturas e compostos) que constituíam o objecto de estudo da química à qual competia, assim, o estudo dos mistos por via da análise.

$\mathrm{Na}$ linha de Johann Joachim Becher (1635-1682), mineralogista dos finais do século XVII, Stahl considerava que a terra e a água eram os princípios chave das substâncias químicas. Existiriam três tipos de terras, a mercurial responsável pelo brilho e maleabilidade dos metais; a vítrea, responsável pela dureza, peso e fusibilidade das substâncias; finalmente, a flogística, ou flogisto, responsável pela combustão dos corpos. No quadro desta teoria, um corpo ardia porque continha flogisto, libertado durante a combustão. Estas três terras eram assim princípios químicos, mas não elementos universais como os quatro elementos de Aristóte- les (terra, fogo, ar e água). Apesar de materiais, não podiam ser isolados, mas eram responsáveis pelas propriedades não só químicas, como físicas dos corpos. Se de uma perspectiva mecânica, o peso era a força com que os corpos são atraídos para terra; de um ponto de vista químico, os corpos eram pesados porque continham terra vitrificável, e, de modo idêntico, ardiam porque continham flogisto. Stahl interpretou ainda a corrosão de um metal como uma combustão lenta, isto é, essencialmente semelhante à combustão viva de um pedaço de madeira ou de carvão.

Na Encyclopédie, Venel subscreve esta tradição e critica a via que considerava subserviente da mecânica. Situada na linha das concepções mecanicistas do século XVII, toda a matéria seria composta dos mesmos corpúsculos (átomos sem qualidades) e distinguia-se entre si pela textura, para usarmos a expressão de Robert Boyle (1627-1691), isto é, pela diferente configuração e arranjo desses corpúsculos. Depois do triunfo da mecânica de Isaac Newton (1642-1727), estes corpúsculos passaram a ser encarados como pequenas massas, sujeitas à lei da atracção universal.

Deste modo, ao conceito de afinidade, que no passado estivera carregado de conotações antropomórficas ao afirmar-se que as substâncias agiam entre si pela maior ou menor simpatia existente entre elas, era agora dado um significado mecânico. Fez-se, assim, a trans-

Figura 3 Exemplares da colecção de minerais de Lavoisier (Panopticum Lavoisier, http://moro.imss fi.it/lavoisier/entrance/panobox.html)
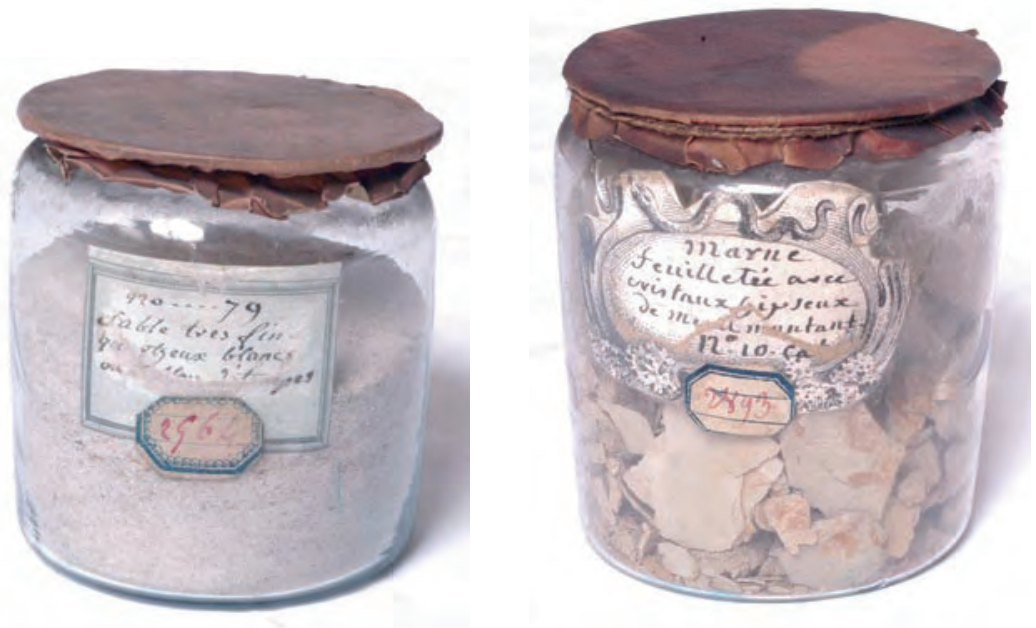


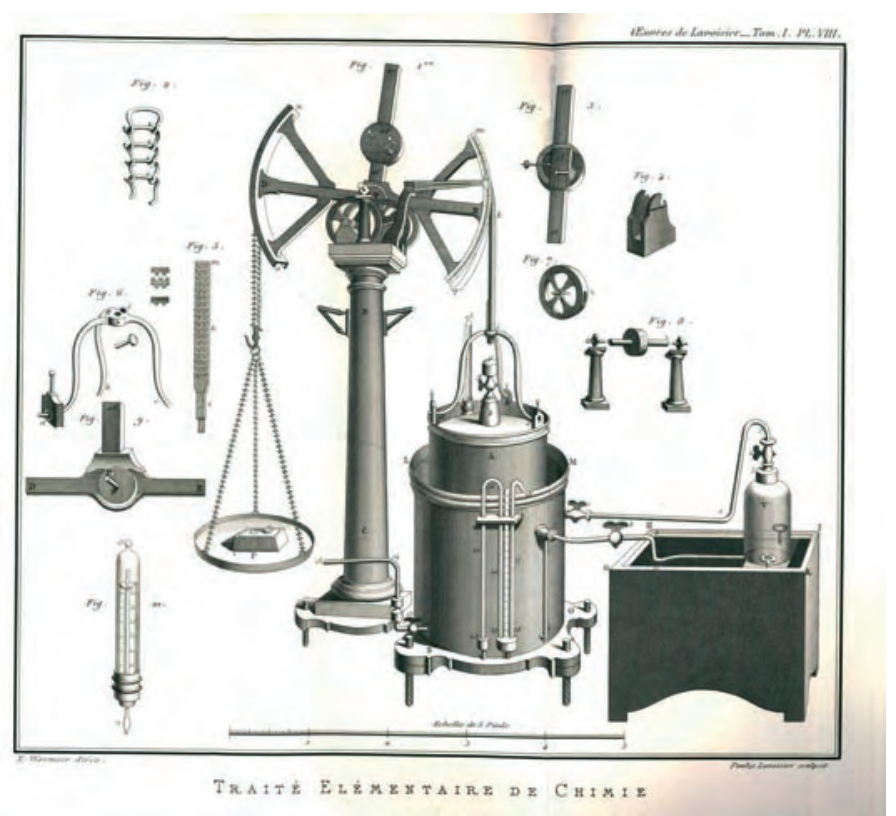

Figura 4 Grauura do gasómetro desenhado por Marie-Anne Paulze, incluida no Traité élémentaire de chimie

posição de uma lei válida no domínio macroscópico, que prescrevia que duas massas se atraem na razão directa do seu produto e na razão inversa do quadrado da distância que as separa, para o domínio do infinitamente pequeno, mas não sem problemas. ${ }^{7}$ De facto, esta era uma interpretação a posteriori, já que não era possível pesar os corpúsculos nem determinar as distâncias que os separavam. No entanto, na senda das precipitações diferenciais que Newton descreveu no Query 31 da Optiks (1704) ${ }^{8}$, diversos e hábeis químicos por todo 0 século XVIII dedicaram longas horas à elaboração das chamadas tabelas de afinidades com vista à determinação das afinidades ou atracções, na esperança de assim submeterem a química ao cálculo e preverem o comportamento das substâncias. ${ }^{9}$ Para Venel esta não era a via a seguir e, como veremos, não será o caminho escolhido por Lavoisier.

\section{Lavoisier no seu tempo}

No século XVIII, para se seguir uma carreira na química as portas de acesso mais comuns eram a farmácia, embora os químicos com esta origem, em França, raramente acedessem às honras da Académie des Sciences; a medicina era outra das vias mais frequentes e, porque gozava de grande prestígio social, os químicos com esta origem alcançavam lugares de docência no ensino superior e na prestigiada Académie; finalmente, a origem industrial, metalúrgica e mineira era socialmente pouco reconhecida em França, mas muito comum na Suécia e nos Estados Germânicos.

Lavoisier não seguiu nenhum destes percursos. Depois de estudar matemática no Colégio Mazzarin com o astrónomo Nicolas de Lacaille (1713-1762), enveredou pelo direito e prosseguiu a sua formação científica com o Abade de Nollet (1700-1770) - então um expoente nas investigações sobre o fluido eléctrico
- botânica com Antoine Laurent de Jussieu (1748-1836), mineralogia com JeanEtienne Guettard (1715-1786), e química com Guillaume-François Rouelle (1703-1770), demonstrador do Jardin du Roi e mestre de Venel. Rouelle era adepto das teorias de Stahl, embora para ele o flogisto tivesse um duplo papel: apesar de ser um princípio, enquanto "matéria do fogo" funcionava também como instrumento nas operações químicas.

Lavoisier iniciou a sua actividade científica pela mineralogia no âmbito da qual efectuou determinações da composição de vários minerais (fig. 3), tendo sido autor com Guettard do Atlas mineralógico de França.

No entanto, preferia o trabalho de laboratório ao trabalho de campo, e, em lugar de se limitar a gozar os prazeres da vida que a sua condição social e meios de fortuna permitiriam, passou a sua juventude a estudar afincadamente. Fez uma carreira brilhante de serviço público, ocupando diversas posições de responsabilidade, que, todavia, o conotaram com o ancien régime e pesaram na sua condenação e execução durante a Revolução Francesa (1789-1799).

As investigações de Lavoisier foram essencialmente feitas nos tempos livres, embora de forma disciplinada: laboratório das 6 às 8 horas da manhã, tarefas administrativas de fermier général e de régisseur des poudres et sâlpetres todo o dia, novamente no laboratório das 19

Figura 5 O casal Lavoisier pintado por David, em 1788, e auto-retrato de Marie-Anne Paulze (Panopticum Lavoisier, http://moro.imss. fi.it/lavoisier/entrance/panobox.html)
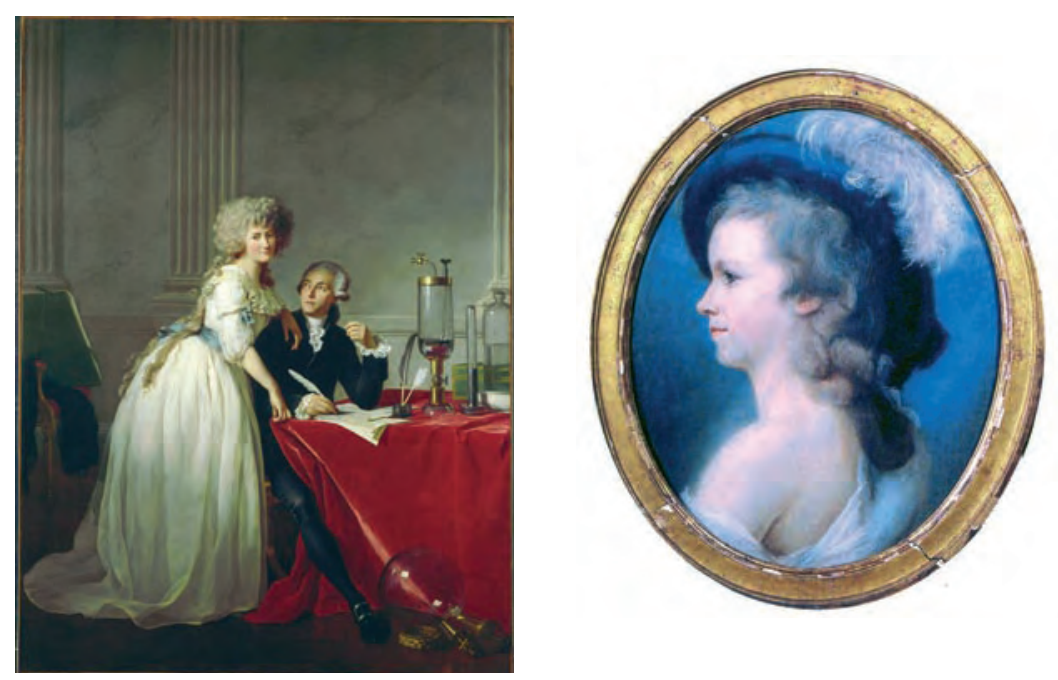
às 22 horas, sendo um dos dias do fimde-semana completamente dedicado à investigação. ${ }^{10}$ Lavoisier tinha rendimentos consideráveis que lhe permitiam gastar verbas avultadas na aquisição de livros e de equipamentos sofisticados e precisos como o gasómetro (fig. 4), que custou uma soma equivalente a $200 \mathrm{mil}$ Euros, ${ }^{11}$ o calorímetro de gelo e balanças de precisão feitas por construtores de instrumentos como Pierre Mégnié (1751-1807) e Jean Nicolas Fortin (17501831).

A gravura do gasómetro, bem como todas as que Lavoisier apresentou no Traité élémentaire de chimie, ${ }^{12}$ foram feitas a partir de desenhos de MarieAnne Pierrette Paulze (1758-1836) com quem casara em 1771.

Discípula do pintor David (1748-1825), Marie-Anne Paulze (fig. 5) esteve longe de ser apenas uma salonière. Inteligente e culta, teve um importante papel não só na ilustração dos trabalhos científicos do marido, abrindo assim um capítulo sem precedentes na ilustração científica da época, como também na colaboração que deu à investigação e na divulgação póstuma da sua obra. ${ }^{13}$
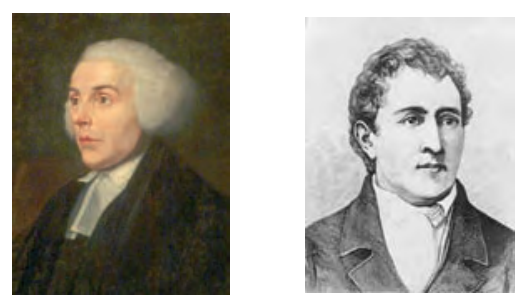

Figura 6 Retratos de Joseph Priestley e Carl Scheele

\section{O Oxigénio}

A "descoberta" do oxigénio está indelevelmente associada ao nome de Lavoisier, bem como a questão de prioridade na descoberta deste gás que disputou com Joseph Priestley (1733-1804) e Carl Scheele (1742-1786) (fig. 6), tema da peça Oxigénio de Carl Djerassi e Roald Hoffmann. ${ }^{14}$ Não retirando importância a esta questão, a obra de Lavoisier foi, no entanto, fundamental muito para além da descoberta do oxigénio.
Comparando as três personagens, Scheele, de nacionalidade sueca, era um homem com uma instrução rudimentar, mais tarde um modesto boticário. Em desvantagem pela sua condição social, pobreza e pelas dificuldades de comunicação, Scheele trabalhou intensamente em investigações químicas, tendo obtido oxigénio, que denominou ar do fogo, por diversos processos entre os quais por aquecimento de óxido vermelho de mercúrio.

Priestley, por seu turno, era teólogo e um dos químicos britânicos mais produtivos do século XVIII, possuindo um laboratório bem equipado com diversos instrumentos construídos pelo famoso John Harrison (1693-1776). Priestley visitara Paris com o seu patrono, Lorde Shelburne, chegando a jantar com Lavoisier, em 1774. Além de dissidente da Igreja Anglicana (negava a Santíssima Trindade), Priestley foi um destacado membro da Lunar Society ${ }^{15}$. Criada em Birmingham, um centro da Revolução Industrial, a Lunar Society congregou personalidades como James Watt (17361819), o inventor da máquina a vapor, Erasmus Darwin (1731-1802), avô de Charles Darwin (1809-1882), e o industrial Josiah Wedgwood (1730-1792), que reuniam mensalmente para discutir assuntos filosóficos, técnicos, económicos e políticos.

O meio científico francês era bastante diferente do britânico. Caracterizava-se por um nível mais alto de especialização e a actividade científica estava mais próxima da profissionalização, sendo regulada pela Académie des Sciences, instituição mais dependente do Estado do que a Royal Society. Na Grã-Bretanha, a actividade científica foi marcada pela iniciativa individual e local, pautava-se por cânones menos rígidos e era dominada por gentlemen amateurs. Enquanto Priestley se movimentava entre gentlemen mais ou menos hábeis e diletantes, cultivando a imagem de um investigador cujas virtudes seriam a modéstia e a abertura de espírito, Lavoisier discutia os seus trabalhos com os confrades da Académie des Sciences, procurando apresentar-se como um investigador qualificado que dominava os assuntos, quer na prática, quer na teoria.
De um ponto de vista epistemológico, pode dizer-se que Priestley, Scheele e Lavoisier foram herdeiros da tradição de Stahl. Todos estavam interessados na busca dos princípios que compõem as substâncias, mas ao contrário de Priestley e de Scheele, Lavoisier irá contestar a existência do flogisto e alterar profundamente a química do ponto de vista teórico e metodológico.

Nos anos de 1770, existia uma verdadeira competição internacional, uma "caça aos ares", graças aos trabalhos dos escoceses Stephen Hales (16711761), William Cullen (1710-1790), Joseph Black (1728-1799), e do próprio Priestley que muito contribuíram para a conceptualização do estado gasoso. Lavoisier, no entanto, toma a dianteira em relação aos adversários, quando desloca a competição de uma caça aos ares, no fundo a busca de um espécime a mais numa colecção, para o estudo da decomposição do ar, ou seja, uma investigação analítica com o objectivo de isolar substâncias cada vez mais simples. Com este deslocamento, a problemática muda, mudando a função das experiências sobre o óxido de mercúrio, que assim deixa de ser o objecto de investigação, para se tornar numa ferramenta analítica. ${ }^{16}$

Lavoisier inverteu ainda o esquema de interpretação da combustão: ela já não era uma desunião em que o flogisto se libertava, mas uma combinação com uma parte do ar que irá baptizar com o nome de oxigénio, em 1787, termo que, literalmente, significa gerador de ácidos, ideia que sabemos incorrecta depois dos trabalhos de Humphry Davy (1778-1829), no dealbar do século XIX. A adesão dos químicos ao oxigénio não foi fácil nem imediata. Priestley, por exemplo, jamais aceitou a teoria do oxigénio. Dos colaboradores de Lavoisier na reforma da nomenclatura química efectuada, em 1787, Claude-Louis Berthollet (17481822) converteu-se em 1785, AntoineFrançois de Fourcroy (1756-1809) ensinou a teoria entre 1786-1787 e Guyton de Morveau (1737-1816), ainda estava hesitante em 1787, isto para mencionarmos apenas os químicos franceses mais próximos de Lavoisier. Entre os conversos mais imediatos, conta-se o 
químico da Universidade de Coimbra, Vicente Coelho de Seabra (1764-1804), autor da obra Elementos de Chimica, um excelente manual escrito em português e publicado entre 1788-1790 ${ }^{17}$ que, todavia, não teve repercussões significativas na sua época. ${ }^{18}$

\section{A reforma da nomenclatura}

Cristais de lua, manteiga de arsénico, flores de bismuto e açafrão de Marte eram nomes dados a algumas substâncias no século XVIII. De significado obscuro e variável e impregnados de exotismo, dificultavam a comunicação e o entendimento entre os químicos. A publicação do Méthode de Nomenclature Chimique, ${ }^{19}$ em 1787, por Guyton de Morveau, Lavoisier, Fourcroy e Berthollet representa uma ruptura com o passado, uma divisão na comunidade química, e uma alteração nos destinos de uma disciplina.

A ideia de reformar a nomenclatura terá partido de Guyton de Morveau que mantinha correspondência com o químico sueco Torbern Bergman (17351784), amigo de Carl Lineu (1707-1778). Lineu, que no século XVIII gozava de um estatuto e respeitabilidade idênticos aos de Newton, tinha criado um sistema de classificação das plantas, tendo por base uma nomenclatura binomial, em que o primeiro nome designava o género e o segundo a espécie. Guyton de Morveau e Bergman pensaram em seguir-Ihe as pisadas, na química. No entanto, a participação de Lavoisier neste projecto imprimiu uma orientação distinta da inicialmente pensada por Morveau. Os nomes que este propunha para as substâncias eram novos, mas meramente convencionais. No Méthode de Nomenclature, as denominações pressupunham uma correspondência entre os nomes e a própria natureza dos objectos. Tinham por isso subjacente a análise laboratorial, uma definição operacional de elemento químico e um princípio regulador das transformações químicas, o princípio da conservação da matéria.

A nomenclatura química baseou-se nas ideias filosóficas de Lavoisier que não eram sequer dominantes nos anos de 1780 , inspiradas que eram no sensualismo do Abade de Condillac (17151780), que irá ser referido no Méthode de Nomenclature e no Traité élémentaire de chimie, onde pode ler-se: ${ }^{20}$

Não pensamos senão através das palavras; as línguas são verdadeiros métodos analíticos; a álgebra mais simples, a mais exacta e a mais adaptada ao seu objecto é simultaneamente uma língua e um método analítico, enfim a arte de raciocinar reduz-se a uma língua bem feita.

É partindo destes pressupostos que Lavoisier dirá, a respeito da nomenclatura: ${ }^{21}$

A impossibilidade de isolar a nomenclatura da ciência e a ciência da nomenclatura faz com que toda a ciência física seja formada por três coisas: a série

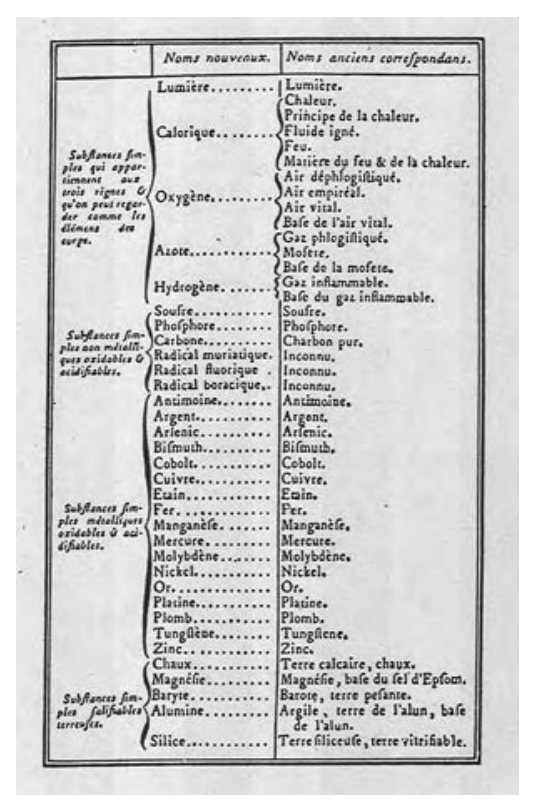

Figura 7 Tabela de Elementos apresentada por Lavoisier no Traité élémentaire de chimie, p.135

dos factos que constituem a ciência, as ideias que os representam, as palavras que os exprimem. A palavra deve fazer nascer a ideia, a ideia deve representar o facto (...) e, como são as palavras que conservam e transmitem as ideias, resulta que se possa aperfeiçoar a linguagem.

Para levar a cabo a reforma da ciência e da nomenclatura, haveria que proceder à análise das substâncias no sentido de encontrar as unidades mínimas de composição, os elementos. Com Lavoisier, o elemento químico ou princípio não é mais uma entidade abstracta, inacessível do ponto de vista laboratorial. Lavoisier tem uma concepção operacional de elemento, definindo-o como o último termo ao qual se chega por via analítica: ${ }^{22}$

Ligamos ao nome dos elementos ou princípios dos corpos, a ideia do termo pelo qual se chega pela análise. Não que possamos assegurar que estes corpos simples não sejam eles próprios compostos de dois ou um maior número de princípios. Mas, uma vez que estes princípios não se separam nunca, ou melhor ainda, uma vez que não temos meios de os separar, eles agem à maneira de corpos simples. E não devemos supô-los compostos, até ao momento em que a experiência e a observação nos forneçam a prova.

Mas a análise química estava associada, por sua vez, a um princípio regulador, o princípio da conservação da matéria. Este princípio estipula que numa transformação química a soma das massas dos reagentes é igual à soma das massas dos produtos, o que implica o uso da balança. A balança há muito que era utilizada nas operações químicas, mas Lavoisier deu-lhe um uso sistemático e converteu-a num instrumento de persuasão e de prova. De modo semelhante, o princípio da conservação da massa também era conhecido, mas tivera até ali um carácter acidental: havia reacções em que ele se verificava, outras não. A diferença essencial é que Lavoisier conferiu a este mesmo princípio um carácter universal - em todas as reacções ele é obrigatoriamente observado.

Os vocábulos para nomear os elementos foram listados numa tabela (fig.7), passando a ser possível, a partir deles, nomear os compostos, no quadro de uma nomenclatura binomial em que, à maneira de Lineu, o primeiro nome designa o género e o segundo a espécie. No entanto, os nomes tinham obrigatoriamente de reflectir a composição química das substâncias como, por exemplo, quando dizemos ácido clorídrico ou cloreto de sódio. 
De notar que da tabela de elementos constam a luz e o calor (calórico). Para Lavoisier, o calórico era, tal como o flogisto havia sido, um fluido subtil ou imponderável, neste caso um princípio de elasticidade, do mesmo modo que o oxigénio era um princípio portador da acidez, concepções que colocam Lavoisier na tradição stahliana. Se é verdade que na célebre "Mémoire sur la Chaleur" (1784) publicada em co-autoria com Pierre-Simon Laplace (1749-1827), ${ }^{23}$ o calor foi submetido a um princípio de conservação e à quantificação, apesar de ambos divergirem quanto à sua natureza, ${ }^{24}$ já quanto à luz, Lavoisier, habitualmente tão rigoroso, preciso e avesso a divagações, não pôde senão divagar, uma vez que a luz não é passível de ser submetida à análise química e permaneceria por longos anos misteriosa: ${ }^{25}$

A organização, o sentimento, o movimento espontâneo, a vida só existem na superfície da terra e nos locais expostos à luz. Dir-se-ia que a fábula de Prometeu era a expressão de uma verdade filosófica que não escapou aos antigos. Sem a luz, a natureza não tinha vida, era morta e inanimada: um Deus benfeitor espalhou sobre a superfície da terra a organização, o sentimento, o pensamento.

Desta revisão das contribuições de Lavoisier fundamentais para a química, caberá ainda referir o que pensava das afinidades ou atracções químicas, esse sonho newtoniano que tanto entusiasmou os seus colegas por toda a Europa: ${ }^{26}$

A parte da química mais susceptível de, talvez um dia, se tornar numa ciência exacta: (é) a que trata das afinidades electivas (...) talvez um sentimento de amor-próprio, sem que eu desse por isso, tivesse dado peso a estas reflexões. O Senhor Morveau está de momento a publicar o artigo "Afinidade" na Encyclopédie Méthodique e eu tenho fortes motivos para duvidar de um trabalho em concorrência com ele.

Como é visível neste excerto, Lavoisier descarta-se airosamente da questão - a afinidade química interessava-Ihe mas, por agora, pouco. No entanto, nas margens da química de Lavoisier ou- tras químicas se fizeram. Na linha das tabelas de afinidades, os químicos começaram a tirar conclusões sobre proporções de combinação: Karl Friedrich Wenzel (1740-1793) e Jeremias Richter (1762-1807), um antigo aluno de Immanuel Kant, fundam a estequiometria com base nas tabelas de equivalentes. Berthollet, por seu turno, concluiu que a acção química depende da massa (concentração) e fez uma "revolução" pelo menos do mesmo calibre da teoria da combustão e do oxigénio, quando afirmou que as reacções incompletas, até então consideradas como simples anomalias, são de facto uma regra geral; enquanto as reacções completas, julgadas normais, se explicam por fenómenos de precipitação ou de volatilização. ${ }^{27}$

Pode assim afirmar-se que, em finais do século XVIII, a química é uma disciplina com uma identidade própria: possui um objecto (a determinação da composição das substâncias), um método (analítico), uma linguagem universal em que os nomes das substâncias reflectem a sua composição, e desenvolve programas de investigação distintos. No século seguinte, irá diferenciar-se em diversas especialidades e profissionalizar-se, mas esta já será outra história...

\section{Notas}

1. Gabriel Venel, "Chymie," in Diderot e d'Alembert, eds., Encyclopédie, ou Dictionnaire Raisonné des Sciences, des Arts et des Métiers, par une Société des Gens de Lettres, Paris, Briasson, David, Le Breton e Durand, 1753, vol. 3, pp. 408-437. Esta tradução e as seguintes são da responsabilidade da autora.

2. Ana Carneiro, O Conceito de Afinidade Química nos Autores do Méthode de Nomenclature Chimique (1787) (Prova de Capacidade Científica), Lisboa, FCUL, 1987.

3. Venel, "Chymie," in Encyclopédie, vol. 3, p. 409.
4. Bernadette Bensaude-Vincent, Lavoisier, Paris, Flammarion, 1993, pp. 62-63.

5. Carneiro, O Conceito de Afinidade, pp. 38-45.

6. Venel, "Chymie," in Encyclopédie, vol. 3, p. 410.

7. Carneiro, O Conceito de Afinidade, pp. 60-70.

8. No Query 31, Newton descreve um conjunto de precipitações diferenciais: uma solução de ferro em água-forte (ácido nítrico) dissolve o cádmio, precipitando o ferro; uma solução de cobre no mesmo ácido dissolve o ferro e precipita o cobre; uma solução de prata em ácido nítrico dissolve o cobre e precipita a prata etc.

9. Carneiro, O Conceito de Afinidade, pp. 81-98.

10. Bensaude-Vincent, Lavoisier, p. 86.

11. O gasómetro foi um dos equipamentos mais caros para além do século XVIII. Trevor Levere, Transforming Matter. A History of Chemistry from Alchemy to the Buckyball, Baltimore e Londres, The Johns Hopkins University Press, 2001, p. 72 e do mesmo autor "Lavoisier's Gasometer and others. Research, Control, and Dissemination" in Marco Beretta, ed., Lavoisier in Perspective, Munique, Deutsches Museum, 2005, pp. 53-77.

12. Antoine-Laurent Lavoisier, Traité élémentaire de chimie (1789), 3. ${ }^{a}$ edição, Paris, 1801, 2 vols.

13. Keiko Kawashima, "Madame Lavoisier. The Participation of a Salonière in the Chemical Revolution" in Marco Beretta, ed., Lavoisier in Perspective, Munique, Deutsches Museum, 2005, pp. 79-94 e Patricia Fara, Pandora's Breeches. Women, Science and Power in the Enlightenment, Londres, Pimlico/ Random House, 2004.

14. Carl Djerassi e Roald Hoffmann, Oxigénio, uma peça em dois actos e 20 cenas (trad. de Manuel João 
Monte), Porto, Universidade do Porto, 2005.

15. O nome da Lunar Society adivinha-Ihe do facto dos seus membros se reunirem mensalmente, na 2.a feira mais próxima da lua cheia, em razão da melhor iluminação de estradas e caminhos, minimizando-se assim a possibilidade de investidas de salteadores.

16. Bensaude-Vincent, Lavoisier, p. 176.

17. Vicente Coelho de Seabra, Elementos de Chimica Offerecidos A Sociedade Litteraria do Rio de Janeiro para uso do seu curso de Chimica, 1. a edição, 1788-1790; 2. ${ }^{a}$ edição (1 vol.), 1985, facsimile publicado pela Faculdade de Ciências e Tecnologia, Departamento de Química, Coimbra. Seabra publicou ainda uma adaptação ao português da nomenclatura química de Lavoisier e colaboradores:
Nomenclatura Chimica Portugueza, Franceza e Latina a que se junta o systema de characteres chimicos adaptados a esta nomenclatura por Hassenfratz e Adet, Lisboa, 1801.

18. Amorim da Costa, Primórdios da Ciência Química em Portugal, Lisboa, ICLP, 1984; Ana Carneiro, Ana Simões, Maria Paula Diogo, "Communicating the New Chemistry in $18^{\text {th }}$ Century Portugal: Seabra's Elementos de Chimica," Science and Education (no prelo)

19. Morveau, Lavoisier, Berthollet e Fourcroy, Méthode de Nomenclature Chimique, Paris, Cuchet, 1787.

20. Lavoisier, Traité in Oeuvres, vol. 1, p. 1.

21. Lavoisier, Traité in Oeuvres, vol. 1, p. 2.

22. Lavoisier, Traité in Oeuvres, vol. 1, p. 7-8.
23. Lavoisier e Laplace, "Mémoire sur la Chaleur" in Lavoisier, Oeuvres, vol. 2, pp. 283-233 e Peter Heering, "Weighing Heat: the Replication of the Experiments with the Ice-calorimeter of Lavoisier and Laplace", in Marco Beretta, ed., Lavoisier in Perspective, Munique, Deutsches Museum, 2005, pp. 27-41.

24. Para Lavoisier o calor era um fluido que impregnaria mais ou menos os corpos, consoante a sua temperatura; para Laplace existiria uma equivalência entre calor e trabalho, sendo o calor a vis viva resultante do movimento das partículas constitutivas de um corpo.

25. Lavoisier, Traité in Oeuvres, vol. 1, p. 142.

26. Lavoisier, Traité in Oeuvres, vol. 1, p. 5.

27. Bensaude-Vincent, Lavoisier, p. 421.

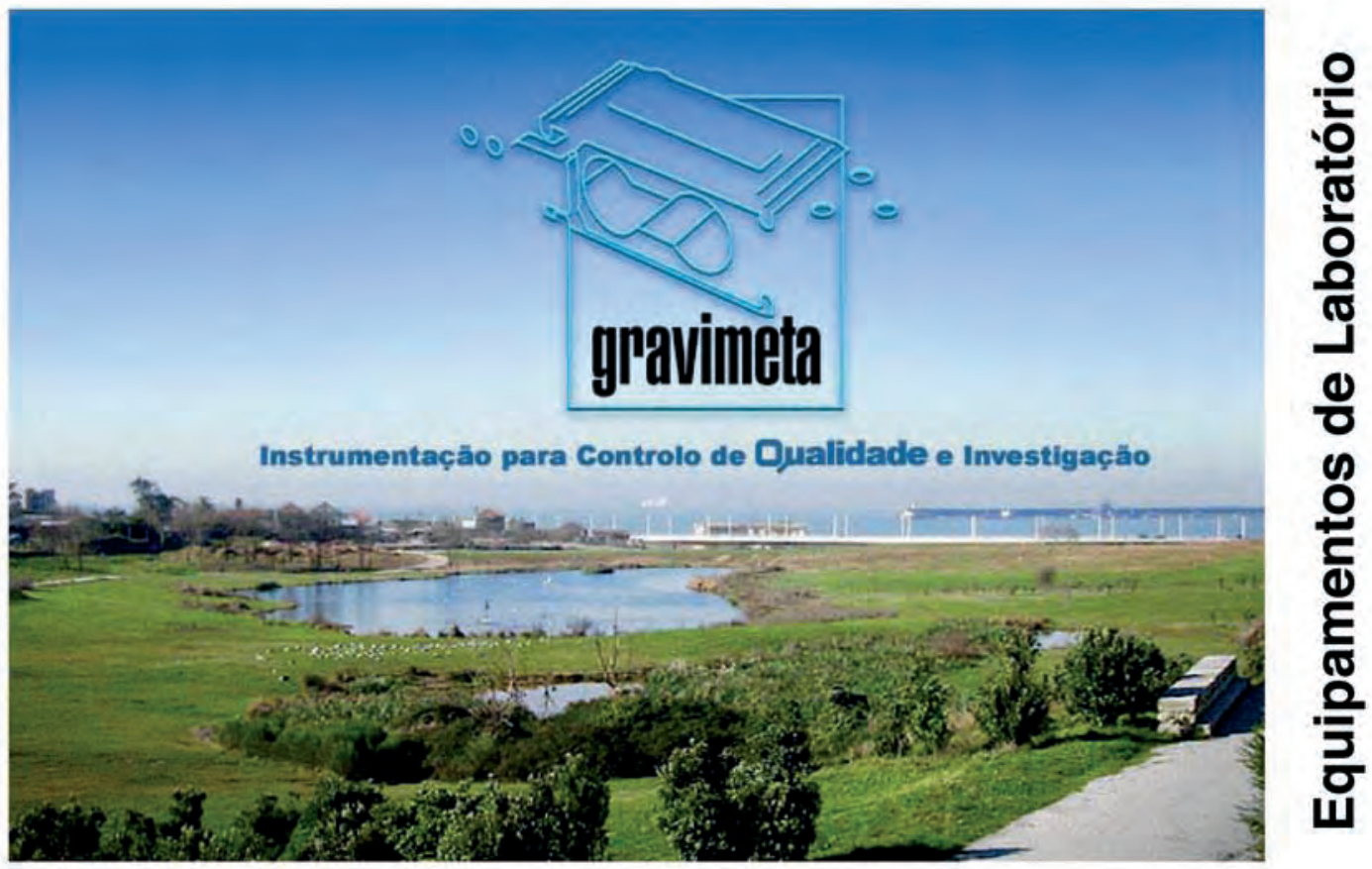

\section{VISITE-NOS EM}

\section{www.gravimeta.pt}

\section{... E DESCUBRA O QUE PODE GANHAR!}




\section{Jasco's \\ Advanced FT-IR Solutions}

\section{Spectra Manager II software \& sampling accessories}

Com uma experiência superior a quarenta anos em espectroscopia de infravermelho, a JASCO oferece as melhores soluções para uma variedade de tipos de amostra com os equipamentos de FT-IR e os acessórios avançados de amostragem. As séries FT/IR-4000 e FT/IR-6000 com software integrado Spectra Manager e os acessórios de amostragem da JASCO melhoram drasticamente os resultados, ao mesmo tempo que reduzem o custo e o tempo de preparação de amostras, bem como das medições.
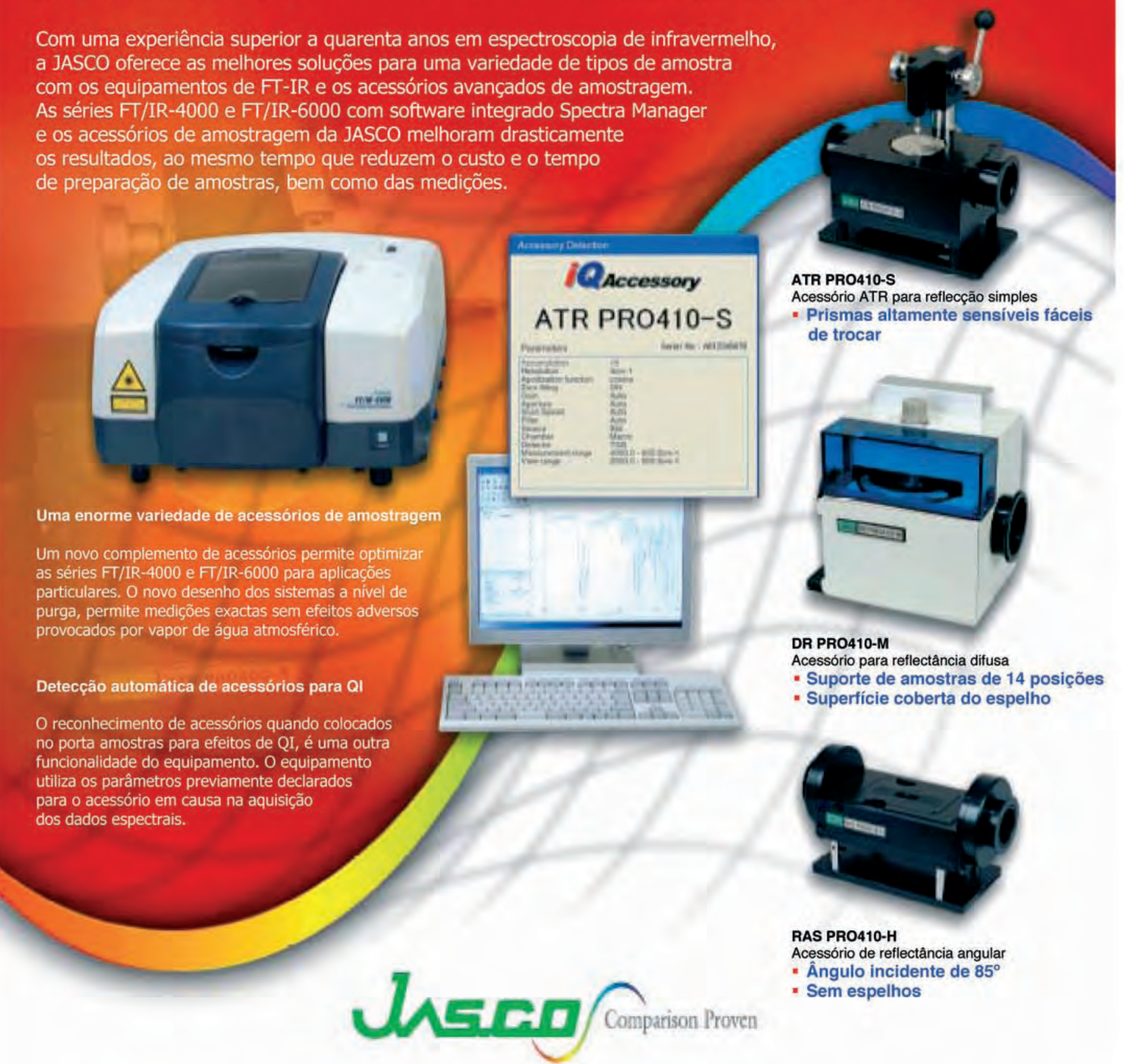

- Suporte de amostras de 14 posições

- Superfície coberta do espelho

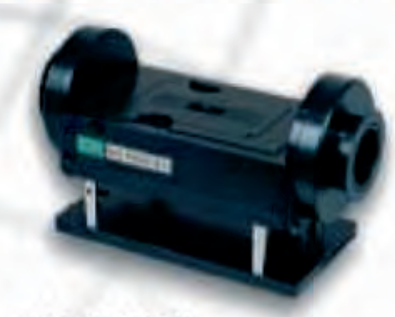

\section{RAS PR0410-H}

Acessório de reflectância angular

- Ângulo incidente de $85^{\circ}$

- Sem espelhos

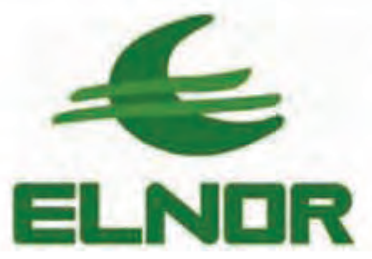

ELNOR - Equipamentos Técnicos e de Laboratório, S.A.

B R.D.Frei Jerónimo de Brito e Melo No 835 • 4465-642 LEÇA DO BALIO • PORTUGAL $\triangle$ P.O.Box $1019 \bullet 4470$ MAIA CODEX • PORTUGAL

- Phone: (351 22) 9050400

- Fax : (351 22) 9050499 